\title{
Latinas' Experience of Sexual Assault Disclosure
}

\author{
Melissa Villarreal \\ Interdisciplinary Health Services (BS-IHS) Program, Western Michigan University, Kalamazoo, USA \\ Email: melissa.villarreal@wmich.edu
}

Received 11 June 2014; revised 8 July 2014; accepted 4 August 2014

Copyright (C) 2014 by author and Scientific Research Publishing Inc.

This work is licensed under the Creative Commons Attribution International License (CC BY). http://creativecommons.org/licenses/by/4.0/

c) $\underset{\mathrm{EY}}{\mathrm{B}}$ Open Access

\begin{abstract}
This study describes Latina's experience of sexual assault disclosure. This study contributes Latinas' voices to the literature on sexual assault disclosure, about feelings experienced during the initial disclosure-regret, shame, and negative judgment of self, and about consequences experienced from the disclosure-feeling spoiled for marriage, silenced, and disbelieved. It points to the need for further research on social interventions to empower Latina sexual assault survivors. Although the literature review identified some research in the area of sexual assault with Latinas, there has been a limited amount of research conducted on feelings and consequences experienced specifically by Latinas during a sexual assault disclosure.
\end{abstract}

\section{Keywords}

Hispanic, Latina, Sexual Assault, Initial Disclosure, Feelings and Consequences

\section{Introduction}

The Latino population is expected to increase to over 30\% of the United States population by 2050 (U.S. Census Bureau, 2008). Latinas are a diverse population with a variety of levels of acculturation, different immigration histories, and different family systems, socioeconomic levels, and attained educational levels (Comas-Diaz \& Greene, 1994). Latino culture is complex and creates the context for differing responses to victimization among Latina sexual assault survivors.

In all the studies reviewed, only $6 \%$ to less than $50 \%$ were Latino participants. In searching the published literature about interpersonal victimization, Cuevas and Sabina (2010) found that only approximately $1 \%$ focused on Latinos. Although the literature review identified some research in the area of sexual assault with Latinas (e.g., Ahrens, 2006; Morrissey, 1998; Ramos-Lira, Koss, \& Russo, 1999; Romero, Wyatt, Loeb, Carmona, \& Solis, 1999; Sorenson, 1996), there has been a limited amount of research conducted on feelings and conse- 
quences experienced specifically by Latinas during a sexual assault disclosure. And the studies that do exist are based on comparisons with other ethnic groups, such as African Americans and non-Latinos White Americans.

Latinas have shown higher rates of nondisclosure of sexual assault than other women from other ethnicities (Arellano, Kuhn, \& Chavez, 1997; Romero et al., 1999). Other research indicated that sex, rape, and abuse are rarely discussed among Latinas (Adames \& Campbell, 2005; Ahrens, Rios-Mandel, Isas, \& del Carmen Lopez, 2010). Furthermore, traditional beliefs about marriage contribute to this reluctance of Latinas to report their sexual assault abuse. With regard to what cultural themes will be beneficial to the current study, a review of current literature on Latinas and sexual assault revealed themes such as the high value placed on virginity (Morrissey, 1998; Ramos-Lira et al., 1999); the likely desire for revenge on the part of a male family member (Bachman, 1998; Fisher, Daigle, Cullen, \& Turner, 2003; Morrissey, 1998; Ramos-Lira et al., 1999); the fear of family shame (Ahrens et al., 2010; Morrissey, 1998; Ramos-Lira et al., 1999); self-blame (Lefley, Scott, Llabre, \& Hicks, 1993; Ramos-Lira et al., 1999); and the shame and embarrassment that accompanies the taboo of discussing topics of sexual relations (Adames \& Campbell, 2005; Ahrens et al., 2010; Romero et al., 1999).

Several studies show that negative social reactions were more likely received by sexual assault survivors disclosing to formal support sources than informal ones (Ahrens, 2006; Campbell, Wasco, Ahrens, Sefl, \& Barnes, 2001; Filipas \& Ullman, 2001; Starzynski, Ullman, Filipas, \& Townsend, 2005; Ullman, 1996a; Ullman, 1996b; Ullman \& Filipas, 2001). A majority of sexual assault survivors are more likely to disclose to informal support sources than formal ones such as the police (Ahrens, Cabral, \& Abeling, 2009; Bachman, 1998; Filipas \& Ullman, 2001; Fisher et al., 2003; Golding, Siegel, Sorenson, Burnam, \& Stein, 1989; Smith, Letourneau, Saunders, Kilpatrick, Resnick, \& Best, 2000; Starzynski et al., 2005; Ullman, 1996a; Ullman \& Filipas, 2001). This reflects the reality that they receive more emotional support from friends and family members than that from formal support sources (Ahrens et al., 2007; Ahrens, Campbell, Ternier-Thames, Wasco, \& Sefl, 2009; Sudderth, 1998; Ullman, 1996b).

Several studies identified that between two thirds and four fifths of sexual assault survivors disclose the assault to at least one person (Ahrens et al., 2007; Fisher et al., 2003; Golding et al., 1989; Starzynski et al., 2005; Ullman, 1996b; Ullman \& Filipas, 2001). Three of the research articles addressed how receiving negative reactions from others during a disclosure may lead to additional psychological trauma (Campbell et al., 2001; McAuslan, 1998; Ullman, 1996b). In addition, self-blame contributes to poor recoveries (Ahrens et al., 2007; Eadie, 2000; Campbell et al., 2001; Routbort, 1998).

After in-depth analysis on narratives given by eight rape survivors (five African American and three non-Latina White) who initially disclosed their sexual assault, but then were silenced for a significant period of time, Ahrens (2006) found that the participants experienced four similar types of negative reactions. These were: “1) being blamed; 2) receiving insensitive reactions; 3) experiencing ineffective disclosures; and 4) receiving inappropriate support” (p. 269). Romantic partners were the most likely to blame the victim and attempt to control the situation, while providing the least tangible aid and providing only moderate emotional support. However, friends and counselors were more likely to provide the most emotional support and tangible aid with not as many negative reactions.

In another study exploring the recovery process, Sudderth (1998) explored women's decisions to delay disclosure or to talk about the rape through a qualitative analysis of 30 survivors' reflections. The author also explored how others' reactions affected these women's subsequent willingness to discuss the rape. Sudderth found a mixture of reactions experienced by most of the participants to some degree; these were distributed into four categories: supportive, inconsistently supportive, silence or avoidance, and hostility. The two most important forms that hostile reaction took were to blame the victim/survivor and to believe that the incident was consensual. In a study that interviewed 102 adult women rape survivors through snowball sampling conducted in urban settings (Chicago metropolitan area) about the social reactions they received from family members and friends after rape disclosure, Campbell, Ahrens, Sefl, Wasco, and Barnes (2001) found that negative reactions may impede survivors' recoveries more than positive reactions. It may be much more beneficial for survivors not to receive any support than to receive negative reactions from others that can lead to hurtful effects on psychological and physical health outcomes.

With regard to feelings experienced, anger has been found to be the most common emotional reaction identified in prior research. Depression, anxiety, fear, guilt, and feeling of being dishonored or spoiled were the other emotional reactions experienced by the sexual assault survivors (Morrissey, 1998; Sorenson \& Siegel, 1992). McAuslan (1998) identified several findings, but only those that relate closely to the consequences of disclosure 
and to the present study are reviewed here. McAuslan's study, the final sample size was 320 female participants, undergraduates from Wayne State University, most of the participants were African American (46\%) or Caucasian (39\%), and seventy-two percent $(n=229)$ of the sample had experienced a sexual assault. With regards to the findings, McAuslan found that participants who received more negative social reactions when they disclosed experienced higher levels of somatic and psychological symptomatology. Next, the study showed that greater expression of emotions during a disclosure was associated with increased experience of anxiety and depression by the sexual assault survivor. Furthermore, Latinas were found to experience higher levels of psychological distress than other ethnicities studied, but were less likely to speak to a psychotherapist about their incident than the non-Latino participants (Lefley et al., 1993; Morrissey, 1998; Sorenson \& Siegel, 1992).

It is in recognition of such limitations, data from 13 Latina sexual assault survivors were analyzed to engage and critique what feelings and consequences are experienced during initial disclosures. Although a number of fairly consistent themes, such as those summarized here, have emerged from prior research, the relevance to the actual experience of sexual assault disclosure can be understood by asking Latina women to narrate their experiences of disclosure. Therefore, this study was designed to use qualitative, semi-structured interviewing techniques to address the following question: What feelings and consequences do Latinas remember experiencing during their initial disclosure?

\section{Method}

\subsection{Recruitment Procedures}

Data was gathered in two waves from Latinas at a women's center for domestic and sexual violence and a center for psychotherapy services. All thirteen Latina participants had been sexually assaulted at least once throughout their life. First data set of seven interviews was gathered in 2005. This initial round of interviews was conducted under a research protocol approved by Hope College's Human Subjects Review Board (HSRB). During 20102011, another six Latinas were recruited to participate in the current study. This phase of the process followed the new research protocol approved by the Human Subjects Institutional Review Board (HSIRB) of Western Michigan University and HSRB of Hope College. At the same time, the data set of the first wave of seven interviews was reapproved for analysis. Recruiting the new set of participants allowed me to add more questions to the interview to further clarify interpretations of decisions to disclose. The participants for the research were female, 18 years and older (the actual participants ranged in age from 18 to 40), Hispanic/Latina (two were Mexican/Mexico-born citizens with United States residency, nine were Mexican American, two were Tejanas/Texasborn Mexican American), and English and/or Spanish speaking.

The participants were recruited through poster announcements and informational flyers that were distributed through the Center's staff counselors, case managers, and in a couple of cases by research participants of this study. Two participants for the second wave were recruited through snowball sampling via referrals by former research participants. As a token of appreciation, each participant received a \$25 gift card for her participation in the research.

\subsection{Procedures}

Semi-structured in-depth interview data were collected for 13 Latinas in the study. The interview schedule used in 2005 was extended in 2010 to focus on feelings and consequences associated with the process of disclosure, at the time of disclosure and in retrospect. The final interview protocol used 25 questions along with gathering the participants' demographics.

Once participants expressed an interest and it was clear that they met qualifications for the study, an interview was scheduled. Sessions were made available on different days and times throughout the week to provide participants with suitable options. All interviews were conducted by this researcher and they took place where each of the participants were recruited from, which was either the women's center for domestic and sexual violence or the center for psychotherapy services. Only one interview took about three hours. The others were completed in an hour or two.

Prior to signing a consent form, the potential participants read the consent form either in English or Spanish or had it read to them in English or Spanish. The consent form indicated that they were not required to participate; if they did participate, they were told they would be allowed to withdraw from the study at any time without 
penalty. Furthermore, they were informed orally and in the consent form that their interviews would be audio-recorded and transcribed into verbatim written documents to be analyzed by the researcher. Participants were all given the option to request to hear the interviewing questions and to reply to them in English, Spanish, or to alternate between both languages. All participants were fluent in either or both Spanish and English, and none of them were ineligible for the study.

\subsection{Analysis Procedures}

As stated earlier, audiotapes were transcribed into verbatim written documents. Most interviewees spoke English throughout their session. However, there were two participants that alternated between speaking English and Spanish. Only one of the two spoke more Spanish than English. On that note, Spanish words, phrases, and/or sentences were italicized and translated into English in parentheses. There is no identifiable information on the written documents of any of the transcribed interviews (i.e., none of the transcribed interviews can be linked to an individual's name). The names used throughout this document and in any future publications are pseudonyms. Prior to analyzing the data, the transcripts were compared to the original tapes and edited for accuracy and readability. A phenomenological method was employed in analyzing the participants' transcripts, primarily by using a constant comparison approach to discern recurrent significant themes that emerged throughout the interviews. These emergent themes were then combined or divided to create the most relevant thematic categories. The process of categorizing served to highlight similarities and differences between the transcripts.

The formal process of data analysis began with documenting detailed field notes immediately following each of the interviews. These field notes provided accounts of the verbal exchanges between the researcher and participants, observations made by the researcher during each of the interviews, and connections made among and about participants' behaviors. All of the points identified in the field notes were taken into consideration as data were reduced, displayed, and analytical themes began to emerge and define themselves more clearly and definitively.

In terms of identifying the themes, a naïve reading was conducted. The interview transcripts were read through from start to finish. No written notes were made during this initial, naïve reading; only mental notes were taken. The transcripts were then re-read and a number of beginning themes, which appeared as important ones were ascertained.

After obtaining initial themes, constant comparison between the data from all the interviews was used to confirm these themes and identify new ones. Constant comparison with the literature was also used to interrogate the data for possible themes identified by others. Once themes and patterns were established, they were tested through an active search of disconfirming data in the form of negative examples, rival explanations, and exceptions to the patterns. In other words, constant comparing occurred back and forth between the literature sources and interviews. The documented themes in the transcripts were color coded. After re-iterating everything, third and subsequence readings were done to flesh out the main themes in the second reading. Saturation of the categories occurred through refining each category by seeking examples of it until no new information yielded additional meaning. Table 1 provides the transcription conventions used in this study.

\section{Results}

Before addressing the research questions, vignettes are used to introduce the respondents and summarize their sexual assault experiences in order to contextualize their personal stories and provide basic demographic information. Pseudonyms are used throughout the vignettes and personally identifying descriptors are avoided, although the ethnicities of the participants are identified using their descriptions. For example, if a participant is identified as Mexican, this means that she described herself as Mexico-born. The term Tejana is used for any Latina who described herself as a Texas-born Mexican American. The term Hispanic/Mexican American is used for

Table 1. Transcription conventions.

Spanish Words and Phrases

English Translations

Interviewees' Pauses
Italicized

In Parentheses

Ellipses 
any Latina who indicated that she was born in America. Mixed ethnic roots (e.g., Mexican-Scottish American) are reported in similar fashion. As stated earlier, most of the participants chose to communicate in English, which might not have been the individuals' native language. Only Adriana chose to alternate between both languages and Raquel used Spanish a few times to clarify her answers. The seven participants from the existing data obtained in 2005 are introduced first; then, the six new participants from the data in 2011 are introduced.

With regard to the types of sexual assault analyzed, it is important to state here that the term sexual assault is interpreted differently by a variety of sources. For the purposes of this dissertation, Michigan's Penal Codes on Sexual Conduct were used to explain the severity level of sexual assault. A CSC I is the most severe sexual assault. This category involves both force and penetration of any type (vagina, anus, or mouth) with a penis, finger, or object such as a pencil (Legislative Council, Act 328 of 1931, 750.520b). The second most severe type of sexual assault is known as a CSC III. This category includes a person engaging in sexual penetration with another person who may have given consent, but did not have the legal right to do so (Legislative Council, Act 328 of 1931, 750.520d). The third most severe type of sexual assault is known as a CSC II. This type of sexual assault includes molestation, pornography, and exploitation of children (Legislative Council, Act 328 of 1931, 750.520c). Finally, the least severe category of sexual assault is known as a CSC IV. It includes a person engaging in sexual contact with another person through a direct or indirect sexual assault such as through indecent exposure (Legislative Council, Act 328 of 1931, 750.520e).

\subsection{Vignettes of Participants' Sexual Assaults}

\section{Sandra}

Sandra was an 18-year-old, single Mexican American who was raped (CSC I) by her mother's stepfather (step-grandfather) when she was 10 years old, while living in Texas with her mother. During a confrontation, Sandra's brother asked Sandra what was leading her to date older men. Sandra was scared, crying, and yelled out that her Grandpa had raped her. It appears that she was only raped once. No other specific details were given about the assault besides that she was penetrated orally and anally. She was 14 years old at the time of the disclosure. Here is what she said about that disclosure:

Well I moved up here (from Texas) when I was 14, and my sister-in-law had me go out with older men, and, I umm... my brother found out and he asked me what was leading me to do this, and that's when I told him... that night, that Grandpa had raped me.

\section{Araceli}

Araceli was a 32-year-old, married and college-educated Tejana. She was a mother of two, who was molested by her grandfather (CSC II) at the age of 7 and raped by two college male acquaintances that she did not know well (CSC I) when she was 18 years old. Araceli did not disclose the first incident until a psychotherapist was completing a psycho-social assessment with her when she was 32 years old. She expressed unclear memories about the exact circumstances that led to the disclosure. Here are her comments about her encounter with the psychotherapist who completed her psycho-social assessment:

I don't know if she (psychotherapist)... I don't know if she was the one who brought it up, or not. I don't know how she brought it up... because of my husband, or something... then she started talking about what has happened during my past or whatever, and it came out.

The second incident was disclosed to a police officer soon after the assault, but then Araceli did not disclose that incident again until she met the psychotherapist mentioned above to have her assessment completed. With regard to this assault, Araceli was raped (CSC I) by two college male acquaintances. A male detective gave Araceli the impression that everyone, including her parents, would find out about the assault if she pursued pressing any charges. She explained the reasons for her discomfort in the following way:

He (the detective) told me that that if I wanted to do that (press charges), that I can do that, but he said "if you tell, you're dead" (it appeared that Araceli felt as if she would die if anyone, her parents, would find out about the rape); more like... "If you charge them, everyone's gonna know, it's gonna be in the paper, and it's gonna be, this is", he said "this is gonna be something that pretty much everyone will know. Your parents will find out”. Then, I just decided "no". 
Araceli stated a couple of times throughout her interview that she had no intention of disclosing her sexual assaults again because of how she was treated by the police officer. At the same time, she did disclose to her psychotherapist and this researcher.

\section{Dominga}

Dominga was a 31-year-old, single, college-educated Tejana who was molested by her biological father (CSC II) at the age of 11 and raped by a male college acquaintance (CSC I) when she was 19 years old. The first incident was not disclosed until Dominga was 26 years old. She disclosed it to a psychotherapist in treatment, then to her mother and brother at a later time. No specific details were provided to the interviewer about the assault or what exactly she disclosed to her psychotherapist, mother, or brother. The only thing she said that she disclosed to anyone was the following: "The incident with my dad, just that he did something, I've never told".

The second incident was disclosed soon after the assault. She was 19 years old when a male college fraternity acquaintance raped her (CSC I) and took her virginity. Dominga and her perpetrator were both at a party celebrating his $21^{\text {st }}$ birthday. After the party, several individuals, including Dominga and her perpetrator, went back to the perpetrator's apartment. Before she realized what was going on, she was upstairs in his bedroom, which was where the rape occurred. Here is her description of what occurred in the perpetrator's bedroom:

I was at a party, drunk, and it was his (the perpetrator's) $21^{\text {st }}$ birthday. We went back to his apartment, where he lived with three other fraternity brothers. Other sorority sisters of mine went with us... And then, people started leaving slowly, and before I knew it, I was up in his bedroom, but his brother and the other sorority girl were in the room next to us... All I remember is passing out, in and out, in and out, and just remembering people laughing, things happening, clothes coming off, and I kept saying: “stop, stop...” And then I'd pass out, wake up to something else, and I remember his other two roommates laughing, and crawling in and out of the room. I was yelling and crying and screaming and he wouldn't stop. I don't know how I got home. I remember the next day, I told him; I called him. I called him and said: "Could I be pregnant? Am I pregnant?” And, he didn’t know what to say. And I remember him saying, "Were you a virgin?” and I said, "Yeah", but I never told him that he raped me. I never said it was a rape. I was just worried about being pregnant.

\section{Feliciana}

Feliciana was an 18-year-old, single, Mexican American who was raped (CSC I) by a male acquaintance in her home when she was 13 years old. Feliciana reported only knowing the perpetrator for a couple of weeks. Disclosure occurred quickly to her parents and the perpetrator was prosecuted and incarcerated. Most of Feliciana's answers to the interviewing questions were quite short. She regretted disclosing because she did not want to experience the court procedures. In other words, Feliciana was uncomfortable sharing her experience in court.

\section{Gabriela}

Gabriela was an 18-year-old, single Mexican American who was raped (CSC I) more than once within a couple of months by a male relative when she was 10 years old. No other details were provided about this perpetrator or the sexual assaults that she experienced except that they were rapes. Gabriela recalled that the disclosure occurred within a few months after the assault, at a time when she felt emotionally supported by a female cousin. When describing her reason for disclosure, Gabriela indicated an awareness of the possible positive value of telling someone. She said:

After talking to my cousin (female cousin), and her being there with me, I had to make it, do it, and it was hard, but you have to deal with it sooner or later, or it's going to eat at you for the rest of your life.

\section{Adriana}

Adriana was Mexican and a 34-year-old mother of three (2-year-old triplets), who was raped (CSC I) by an uncle when she was 10 years old. It took Adriana about 20 years to make her first disclosure, and she disclosed to her boyfriend because he wanted to have a sexual relationship with Adriana. Below, is how she explained what led to her disclosure:

Porque (Because) my boyfriend been asking me when was I going to have sex with him. That's when I told him what happened 20 years ago and after I told him that thing; he was more, mas malo (he was meaner).

After this disclosure to her boyfriend, she indicated that she was blamed and mistreated by him. Here is an excerpt of her description of her boyfriend's reaction to the disclosure: 
I told him what happened and after I told him he said, “I don't want to do sex with you cause you're gross; you have sex with your uncle, yuck”. I didn’t go into detail... He (boyfriend) abused me psychologically.

\section{Teresa}

Teresa was a 34-year-old, mother of two, Mexican and Scottish American who was molested (CSC II) by an older biological brother when she was 10 years old. It took her about 4 years to disclose. The disclosure occurred upon his return home from the Marines. Teresa felt that she had to tell a friend what he had done to her when she was 10 to protect herself. Below, she explained her brother's home coming and what led to her first sexual assault disclosure:

My stepfather died all of a sudden and everybody was talking about how my brother was coming home. He was in the Marines. I had to prepare for him to stay at our house. And I... I didn’t want him there. I was so glad when he left. And I... it was hard... I had a friend of mine; he was kind of like a brother to me. He was older than I am. And, I confided in him, but he didn't believe me. He went and told my mom about it. Of course, my mom didn't believe me either. So, my mom called my brother in California. There, where he was stationed and asked him about it. Thankfully for him, he was going to church and stuff. He admitted to it. When he came home; he didn't stay at the house.

\section{Veronica}

Veronica was a 21-year-old, single, college-educated Mexican American who witnessed an indecent exposure incident (CSC IV) by a stranger when she was about 10 or 11 years old and working as a school safety guard. Disclosure occurred within minutes and the perpetrator was prosecuted.

\section{Raquel}

Raquel was a 20-year-old, single, college-educated Mexican American who had been raped several times by two former boyfriends. The first rape (CSC I) occurred when she was 12 years old. The first perpetrator was a family acquaintance, possibly a distant relative that resided with the family during migrant seasons (OctoberApril). He was an illegal alien from Mexico who had pursued an intimate relationship with her prior to the rape. This first perpetrator was identified to a physician when she was 13 years old in the course of a routine examination. With regard to the second perpetrator, he assaulted Raquel several times when she was 18 years old during their relationship. Raquel reported feeling pressured every time they had sex, but she did not really know how to advocate for herself.

\section{Magdalena}

Magdalena was a 20-year-old, single, college-educated woman, who identified herself as Mexican. She reported being molested (CSC II) several times by an older male cousin when she was 6 or 7 years old. Magdalena has not disclosed these assaults to anyone except this researcher. It was important for her to know that this information would remain confidential. Here are her comments on confidentiality of the disclosure:

It's just like I feel like... I, um, that I feel like I can talk to you and I can actually let you know and it's going to stay just between us.

\section{Cynthia}

Cynthia was a 22-year-old, single, college-educated Mexican American who was molested (CSC II) by an uncle by marriage when she was 13 or 14 years old. She has only disclosed these incidents to her fiancé, college roommate, and to this researcher. Cynthia recalled two sexual assault incidents that she experienced by her uncle. He uncle rubbed his hand down Cynthia's body from her shoulder down to her knee, but never actually touched her breasts, buttocks, or vagina. At the same time, Cynthia stated that she felt uncomfortable and possibly violated. Cynthia's maternal aunt is no longer married to the perpetrator (Cynthia's uncle by marriage).

\section{Gloria}

Gloria was a 36-year-old, married, mother of two, college-educated Mexican American who had experienced three different sexual assaults. Gloria decided to participate in the current interview to disclose an assault as a first step toward healing. The first incident occurred when she was about 5 or 6 years old; an older Latino male in the neighborhood molested her (CSC II). This incident was not disclosed until the day she was interviewed for this study. She met with her Godmother prior to the interview and practiced sharing her stories.

The second incident occurred when she was 6 years old; an African American male used vulgar language to verbally assault her (CSC IV). Gloria disclosed within minutes, but her biological mother ignored her. They 
were all at a neighbor's house party. From this incident, Gloria was silenced for about 30 years.

She did not disclose the third set of assaults until a night of drinking with her older sister. As she revealed to the current researcher, the final set of incidents occurred when Gloria was between the ages of 10 and 14 years. Her mother's boyfriend molested her over a period of several years. The disclosure occurred after her older sister shared with them (Gloria, younger sister, and their mother) that their stepfather (their mother's former boyfriend) raped her (CSC I).

\section{Leticia}

Leticia was a 40-year-old, divorced once, but currently married, mother of five. She is a Mexican American who was not only molested (CSC II) several times between the ages of 10 to 14 years but raped (CSC I) once when she was 14 years old by her first stepfather. The abuse was reported to the police when she was about 15 years old. Leticia's mother informed Leticia that she (Leticia) refused to follow through with testifying for the prosecution. Leticia did not recall the court proceedings, but her mother informed her about how she walked out of court after stating, “I wasn't doing it”. It appeared that Leticia chose not to testify against her perpetrator (her first stepfather), but has repressed that memory. Here is what she said when she refused to testify against her stepfather in court:

I guess I went into the courtroom and I don’t know, I froze, she said and I walked out, said I wasn’t doing it.

\subsection{Demographic Characteristics of Participants}

Table 2 provides a short description of each of the participants for reader reference. It identifies their pseudonyms, ethnicity, age at the time of first assault, age during the interview, and year interview was conducted. The women's ages at the time of the interview range from 18 to $40(M=26.5)$. Two of the women identified themselves as Mexican (Mexico-born), two as Tejanas (Texas-born Mexican Americans) and the other nine identified as either or both Hispanic and Mexican American.

Table 3 presents aggregate findings of the descriptive information for the 13 Latina participants in the current study. Most of the participants were single at the time that the interviews were conducted $(n=8 ; 61 \%)$. In addition, Table 2 reveals that the majority of the participants' first sexual assault incidents happened when they were young children between the ages of 6 and 11 years old $(n=10 ; 77 \%)$. Only three $(23 \%)$ of the participants were sexually assaulted as adults. A very low percentage of the participants $(n=2 ; 15 \%)$ made their first disclosure of any of their assaults to professionals including enforcement officials. In 10 cases (77\%), the participants/survivors made their first disclosure to either a friend, including significant other, or a family member. In addition, two participants (15\%) who had disclosed at least one of their sexual assault incidents had never disclosed a sexual assault incident(s) until they agreed to participate in this study. In other words, while describing their experience of disclosing a sexual assault, Araceli and Raquel disclosed additional assaults they had not talked to anyone about. The majority of the participants $(n=12 ; 92 \%)$ knew their perpetrators. Furthermore, nine $(69 \%)$

Table 2. Description of participants at age at time of first assault and time of interview.

\begin{tabular}{|c|c|c|c|c|}
\hline Pseudonyms & Ethnicity & Age at the time of first assault & Age at the time of the interview & Year interviewed \\
\hline Sandra & Hispanic & 10 years old & 18 years old & 2005 \\
\hline Araceli & Chicana/Tejana & 7 years old & 32 years old & 2005 \\
\hline Dominga & Latina/Tejana & 11 years old & 31 years old & 2005 \\
\hline Feliciana & Hispanic & 13 years old & 18 years old & 2005 \\
\hline Gabriela & Hispanic & 10 years old & 18 years old & 2005 \\
\hline Adriana & Mexican & 10 years old & 34 years old & 2005 \\
\hline Teresa & Mexican-Scottish American & 10 years old & 34 years old & 2005 \\
\hline Verónica & Mexican American & 10 or 11 years old & 21 years old & 2011 \\
\hline Raquel & Mexican American & 12 years old & 20 years old & 2011 \\
\hline Magdalena & Mexican & 6 or 7 years old & 20 years old & 2011 \\
\hline Cynthia & Mexican American & 13 or 14 years old & 22 years old & 2011 \\
\hline Gloria & Mexican American & 5 or 6 years old & 36 years old & 2011 \\
\hline Leticia & Mexican American & 10 years old & 40 years old & 2011 \\
\hline
\end{tabular}


Table 3. Demographics and selected characteristics of participants and sexual assault incidents.

\begin{tabular}{|c|c|c|c|c|c|c|}
\hline \multirow{2}{*}{ Demographics } & \multicolumn{2}{|c|}{ Existing data from $2005(n=7)$} & \multicolumn{2}{|c|}{ Data collected in $2011(n=6)$} & \multicolumn{2}{|c|}{ Total $(n=13)$} \\
\hline & $n$ & $\%$ & $n$ & $\%$ & $n$ & $\%$ \\
\hline \multicolumn{7}{|l|}{ Marital status at the time of interview } \\
\hline Single & 4 & 57 & 4 & 67 & 8 & 61 \\
\hline Married & 2 & 29 & 2 & 33 & 4 & 31 \\
\hline Divorced or separated & 1 & 14 & 0 & 0 & 1 & 8 \\
\hline \multicolumn{7}{|l|}{ Age at the time of the first assault } \\
\hline Early childhood (1 - 5 y/o) & 0 & 0 & 1 & 17 & 1 & 8 \\
\hline Childhood (6 - 12 y/o) & 6 & 86 & 4 & 66 & 10 & 77 \\
\hline Adolescent (13 - 17 y/o) & 1 & 14 & 1 & 17 & 2 & 15 \\
\hline Adult $(17+)$ & 0 & 0 & 0 & 0 & 0 & 0 \\
\hline \multicolumn{7}{|l|}{ Assaulted as an adult after first assault } \\
\hline Yes & 2 & 29 & 1 & 17 & 3 & 23 \\
\hline No & 5 & 71 & 5 & 83 & 10 & 77 \\
\hline \multicolumn{7}{|l|}{ Person to whom first disclosed } \\
\hline Professional & 1 & 14 & 1 & 17 & 2 & 15 \\
\hline Survey & 0 & 0 & 1 & 17 & 1 & 8 \\
\hline Friend & 2 & 29 & 1 & 17 & 3 & 23 \\
\hline Family member & 3 & 43 & 2 & 33 & 5 & 39 \\
\hline Significant other (Boyfriend) & 1 & 14 & 1 & 17 & 2 & 15 \\
\hline \multicolumn{7}{|l|}{ Severity of most severe assault } \\
\hline Mild severity (CSC IV—No Contact) & 0 & 0 & 1 & 17 & 1 & 8 \\
\hline Moderate severity (CSC II—Molestation) & 1 & 14 & 3 & 50 & 4 & 31 \\
\hline Average severity (CSC III—Penetration) & 0 & 0 & 0 & 0 & 0 & 0 \\
\hline Most severe (CSC I—Penetration) & 6 & 86 & 2 & 33 & 8 & 61 \\
\hline \multicolumn{7}{|l|}{ Perpetrator of first assault } \\
\hline Stranger & 0 & 0 & 1 & 17 & 1 & 8 \\
\hline Date or acquaintance & 1 & 14 & 2 & 33 & 3 & 23 \\
\hline Family member & 6 & 86 & 3 & 50 & 9 & 69 \\
\hline Significant other (Boyfriend) & 0 & 0 & 0 & 0 & 0 & 0 \\
\hline \multicolumn{7}{|l|}{ Time of disclosure for first assault } \\
\hline$<24 \mathrm{~h}$ after the assault & 1 & 14 & 1 & 17 & 2 & 15 \\
\hline 1 day $-<1$ month & 0 & 0 & 0 & 0 & 0 & 0 \\
\hline 1 month $-<1$ year & 1 & 14 & 0 & 0 & 1 & 8 \\
\hline 1 year - 5 years & 2 & 29 & 2 & 33 & 4 & 31 \\
\hline 6 years -10 years & 0 & 0 & 1 & 17 & 1 & 8 \\
\hline$>10$ years after the assault & 3 & 43 & 2 & 33 & 5 & 38 \\
\hline \multicolumn{7}{|l|}{ Number of assaults } \\
\hline 1 assault & 4 & 57 & 1 & 17 & 5 & 39 \\
\hline 2 assaults & 2 & 29 & 1 & 17 & 3 & 22 \\
\hline 3 or more assaults & 1 & 14 & 4 & 66 & 5 & 39 \\
\hline
\end{tabular}


of the participants identified their first perpetrator as a family member. More than half $(n=10 ; 77 \%)$ of the participants took over a year to disclose their first sexual assault incident, whereas two of the other three participants disclosed within 24 hours. Feliciana was raped by an acquaintance in her home. She disclosed the incident to her parents right after he left the residence. Veronica experienced a incident exposure; she was flashed a penis by a stranger while working as a safety guard by a school street corner. She disclosed the incident to a teacher right away, within minutes. Fewer than half of the participants $(n=5 ; 39 \%)$ experienced only one sexual assault, but eight participants (61\%) experienced two or more sexual assaults, some by different perpetrators at different points in time.

\section{Phenomenological Analysis: Common Experiences and Central Themes}

The previous vignettes provided short, contextualized descriptions of each participant's sexual assault experiences. The common experiences and central themes of the current study have been organized addressing the research question guiding this study. They are presented below through tables and with selected quotes for illustration.

Research Question: What feelings and consequences do Latinas remember experiencing during their initial disclosure?

In this section, feelings and consequences experienced by Latina sexual assault survivors during their initial sexual assault disclosure were identified. The data reduction phase identified nine types of feelings experienced by the participants in this study: regret, shame/embarrassment, negative judgment of self, worry, fear, anger, relief, depression, and hatred. As can be seen in Table 4, regret was the most often felt feeling $(n=7 ; 54 \%)$.

In Araceli's case, she regretted contacting the police soon after her rape for two reasons. First, she felt unsupported by the police officer that took her statement. It appeared that Araceli was convinced not to press charges because she was informed that her parents would find out, which scared her because she did not want her parents to judge her. Second, Araceli regretted that the police officer took her to an emergency room (ER) for a sexual assault examination. Araceli expressed that it was a very uncomfortable examination to experience. Here are the two sections of her interview in which she described feeling regret:

Interviewer: What led you to disclose?

Araceli: I was scared. I didn't know. I was thinking; I was thinking about, um, what if I was going to have a baby? Or, if I had gotten a disease? I was thinking that $\cdots$ That was a bad thing that they did. I didn't think it was right $\cdots$ So, I had to call them (the police). I didn't know who else to call. I did feel like I needed to tell them. But then when I did call, and I did go through with it, I thought, maybe I shouldn't have called someone. They wouldn't have taken me to the emergency $\cdots$

Interviewer: They took you to the emergency room? That's where they did all the examination, collected all the evidence? That's why they cut your clothing?

Araceli: Yeah.

Table 4. Feelings experienced during initial disclosure.

\begin{tabular}{|c|c|c|c|c|c|c|}
\hline \multirow{2}{*}{ Themes } & \multicolumn{2}{|c|}{ Existing data from 2005} & \multicolumn{2}{|c|}{ Data collected in 2011} & \multicolumn{2}{|c|}{ Total $(n=13)$} \\
\hline & $n$ & $\%$ & $n$ & $\%$ & $n$ & $\%$ \\
\hline Regret & 2 & 29 & 4 & 67 & 6 & 46 \\
\hline Shame/Embarrassment & 4 & 57 & 1 & 17 & 5 & 39 \\
\hline Negative judgment of self & 1 & 14 & 2 & 33 & 3 & 23 \\
\hline Worry & 2 & 29 & 1 & 17 & 3 & 23 \\
\hline Fear & 1 & 14 & 2 & 33 & 3 & 23 \\
\hline Anger & 0 & 0 & 2 & 33 & 2 & 15 \\
\hline Relief & 0 & 0 & 2 & 33 & 2 & 15 \\
\hline Depression & 0 & 0 & 1 & 17 & 1 & 8 \\
\hline Hatred & 0 & 0 & 1 & 17 & 1 & 8 \\
\hline
\end{tabular}


Interviewer: Do you regret anything about the disclosure?

Araceli: No and yes. I regret calling the police, but I don't regret telling my psychotherapist. I'm glad I told her because somebody listened.

Interviewer: Feeling heard?

Araceli: Yeah. My mom probably wouldn’t understand like my psychotherapist does. She would think badly of me. My mother would probably... I don't know. I think she would have thought or something... She would have thought... You know? Like, I was dumb or something. I don't know. I always thought, because I'm the only one who went to college. I should have known all that, right? My psychotherapist, because, I don't think she’s gonna tell me anything and she hasn’t... Isn’t judging me or...

The next four most often felt feelings were shame/embarrassment ( $n=5 ; 39 \%$ ), negatively judging themselves $(n=3 ; 23 \%)$, worry $(n=3 ; 23 \%)$, and fear $(n=3 ; 23 \%)$. The only positive feeling identified by two participants (15\%) was relief. With regard to shame/embarrassment, Araceli was taken to the emergency room by a police officer soon after she was raped by two college male acquaintances. She reported that the emergency room visit was an embarrassing experience for her and wished she would not have been taken there. Here, she clearly expressed her feelings of shame and embarrassment:

I wouldn't, I wouldn't have gone... Cause it was, embarrassing, I felt like, I don’t know, something to examine, I felt really gross, and I didn’t want people looking at me. They were all looking at me $\cdots$ And checking me, and I wouldn't have gone if I knew that, but it was, I just kind of stood there and let them do what they did because it was embarrassing. And to know what they knew... Kind of makes you feel like, I don't know.

With regard to consequences, mistreatment was the most often experienced consequence ( $n=4$; 31\%), a sense of feeling spoiled was the second most often experienced consequence ( $n=3 ; 23 \%)$, and the lack of support was the third most often experienced consequence $(n=2 ; 15 \%)$. A sense of being ignored, feelings of negative selfworth, an increased sense of being self-guarded, a sense of being silenced, a feeling that one was not believed, and a lack of confidentiality were also experienced. As can be seen in Table 5, the other seven consequences were each identified only once. In Gloria's case, her older sister verbally assaulted Gloria for not disclosing her sexual assault incidents by their mother's boyfriend earlier. Gloria's sister was angry because their mother did not believe that she was assaulted as an adolescent, but if Gloria would have also discussed her assault when Gloria's older sister did, then maybe their mother would have believed them. This is how Gloria explained her older sister's reaction to her disclosure:

She was angry because she felt like if I would have said something before, my mom might have listened to her before and got us out of the situation. So, she blamed me for not speaking up.

Feeling spoiled for marriage or a significant relationship was the second most identified consequence experienced during an initial disclosure. In Dominga's case, once she lost her virginity, she reported feeling like damaged goods. Here is what she said about how no one may want to marry her:

Fear that I wouldn't have been believed, that I would be blamed, that a man wouldn't want to be with me, that I was no longer seen as a good girl because I lost my virginity to the rape. I'm Catholic. I feel like I'm damaged goods, I don’t know if anyone will ever marry me.

There was no elaboration on this topic. Dominga simply stated feeling spoiled for marriage. At the time of the interview, she was single and had had very little dating experience.

\section{Conclusion}

This phenomenological study identified a number of themes based on the actual stories of sexual assault disclosures given by 13 Latina survivors. Regret and shame/embarrassment were the most often experienced feelings during initial disclosures identified by the Latinas; these were followed by negative judgment of self, worry, fear, anger, relief, depression, and hatred. With regard to consequences, nine themes were identified. Feeling mistreatment, having a sense of feeling spoiled for marriage, and sensing a lack of support were the most often felt consequences. Other consequences experienced were a sense of being ignored, feelings of negative self-worth, an increased sense of being self-guarded, a sense of being silenced, a feeling that one was not believed, and 
Table 5. Negative consequences experienced during initial disclosure.

\begin{tabular}{|c|c|c|c|c|c|c|}
\hline \multirow{2}{*}{ Themes } & \multicolumn{2}{|c|}{ Existing data from $2005(n=7)$} & \multicolumn{2}{|c|}{ Data collected in $2011(n=6)$} & \multicolumn{2}{|c|}{ Total $(n=13)$} \\
\hline & $n$ & $\%$ & $n$ & $\%$ & $n$ & $\%$ \\
\hline Mistreatment & 3 & 43 & 1 & 67 & 4 & 31 \\
\hline Spoiled for marriage & 2 & 29 & 1 & 17 & 3 & 23 \\
\hline Lack of support & 2 & 29 & 0 & 0 & 2 & 15 \\
\hline Ignored & 0 & 0 & 1 & 17 & 1 & 8 \\
\hline Negative self-worth & 0 & 0 & 1 & 17 & 1 & 8 \\
\hline Self-guarded & 0 & 0 & 1 & 17 & 1 & 8 \\
\hline Silenced & 0 & 0 & 1 & 17 & 1 & 8 \\
\hline Wasn't believed & 0 & 0 & 1 & 17 & 1 & 8 \\
\hline Lack of confidentiality & 1 & 14 & 0 & 0 & 1 & 8 \\
\hline
\end{tabular}

fearing a lack of confidentiality.

\section{Discussion}

In working with Latina women, it is important to understand and gain awareness about the potential commonalities they may have with other women in their communities, while being open to each individual's unique narrative and life story (Comas-Diaz \& Greene, 1994). Ahrens, Isas, and Viveros (2011) recommended that more qualitative and participatory methods of collecting data and conducting research with Latinas would reduce isolation and empower Latina survivors of sexual assault than quantitative methods. This study fills the need identified by Ahrens and colleagues.

\subsection{Interpretation of Results}

\subsubsection{Nature of Assault and Circumstances of First Disclosure}

The qualitative data yielded several themes that both support and expand on previous findings regarding the nature of assaults and disclosure. First, most of the women were sexually assaulted for the first time before the age of 13 years (77\%). The median age at the time of the first sexual assault for Latina victims was about 10 years. These results are consistent with findings reported by Romero et al. (1999) suggesting that childhood rape and childhood sexual abuse may actually be higher than reported in other studies of Latinas.

In the current study, 7 (54\%) participants disclosed their sexual assault for the first time to a family member or a significant other (current boyfriend) and only 2 of the 13 informants had first disclosed their sexual assault to a professional. This may mean that they also are unlikely to seek counseling and assistance from a mental health professional. Indeed only 5 of the women (Dominga, Feliciana, Adriana, Teresa, and Leticia) had sought psychotherapy following their disclosure. This number may actually be high as the recruitment of participants occurred through a counseling center this number might be artificially high. One other interesting occurrence in this study was that 2 (Araceli and Raquel) of the participants chose to use the research interview as an opportunity to disclose incidents of sexual assault that they had never shared with others, however, they had already disclosed at least one sexual assault incident prior to their interviews. The research interview was perhaps perceived as a safe place and/or a reason to disclose the information.

In this study, 2 of the 13 participants (15\%) were victimized as college women by male college acquaintances. Only 1 participant, Araceli, disclosed the incident to the police. Araceli was raped by two college male acquaintances. She reported feeling ignored about the situation. The police officer scared her into not pursuing legal charges by informing her that everyone would find out about the assault, including her parents. Araceli was afraid of how her parents would react. She thought they would negatively judge her. In retrospect, Araceli regretted her disclosure in part because the police officer transported her to an ER for a sexual assault examination. This experience led Araceli to feel embarrassed. She also regretted her decision to disclose because she felt mistreated by the police officer. Fisher et al. (2003) reported that only a very low percentage of sexually victimized 
college women in their study reported their incidents to the police and that these victimizations were later disclosed to others.

\subsubsection{Feelings and Consequences Experienced during Initial Disclosure}

As shown in the literature, Sorenson and Siegel (1992) reported that 59\% of their participants experienced anger as their most common emotional reaction to a sexual assault. Depression (43\%), anxiety (40\%), fear (35\%), guilt (32\%), and feeling of being dishonored or spoiled (29\%) were the other emotional reactions experienced by the participants. However, this current study collected data on feelings experienced during initial disclosures, which is not the same as feelings experienced due to the sexual assault. McAuslan (1998) found that greater expression of emotions during a disclosure was associated with increased experience of anxiety and depression by the sexual assault survivor.

In contrast to these other articles, the current study found that regret was the most common emotion experienced during the initial disclosure. Regret was experienced by more than half of the participants $(n=6 ; 46 \%)$. Shame/embarrassment $(n=5$; 39\%), negative judgment of self $(n=3 ; 23 \%)$, feeling spoiled for marriage $(n=3$; $23 \%)$, worry $(n=3 ; 23 \%)$, fear $(n=3 ; 23 \%)$, anger $(n=2 ; 15 \%)$, relief $(n=2 ; 15 \%)$, depression $(n=1 ; 8 \%)$, and hate $(n=1 ; 8 \%)$ were the other emotions experienced by the participants.

The difference that exists between the current study and the published literature with regard to what feelings are experienced following sexual assault disclosure may be due to when the respondents are asked about their emotional reactions. I specifically looked at the feelings felt during the initial disclosure, whereas Sorenson and Siegel (1992) may have referred to how their respondents felt soon after the assault instead of after the disclosure. In all, there are some similarities, but this study expanded the range of feelings described by Latina sexual assault survivors.

As shown in Table 4, 11 of the 13 participants (85\%) took at least a month to make their first disclosure. Emotional reactions to a sexual assault may be very different from the emotional reactions to the disclosure of it. Some individuals need time to deal with their initial feelings of anger, shock, or confusion from an assault first by keeping to themselves instead of showing their true feelings to others. In other words, these individuals disappear into their own "caves" and cope with their initial feelings, then, once they have gained the strength and courage to disclose, they do. Feelings felt during the disclosure would then be different than the initial feelings experienced.

With regard to consequences experienced during initial disclosure in this study, mistreatment had the highest occurrence. Four participants (31\%) experienced some type of mistreatment. Adriana was rebuked by her boyfriend; Araceli was treated harshly by the police; Dominga was treated unfairly by her sorority sisters; and Gloria was ignored by her mother. Ahrens et al. (2007) found that those who disclosed their sexual assault to a formal support, such as the police, were more likely to receive a negative social reaction than a positive one. Conversely, those who disclosed to an informal support, such as a friend, were more likely to receive a positive social reaction than a negative one. In this study, of the three who reported to the police, only Araceli received a negative social reaction or felt mistreatment. The other two did not report any mistreatment. The reason the two participants, Feliciana and Veronica, received positive social support from the police may have been because they were children during their disclosure, while Araceli was a young adult and was more harshly treated by the authorities. The authorities may have blamed Araceli for the rape she experienced.

Campbell et al. (2001) recommended in their study of adult sexual assault survivors that families, friends, and significant others of sexual assault survivors should be taught how to avoid negative reactions when attempting to provide support. They felt that it was better to provide no support than to react negatively. Ullman (1996b) found that $63 \%$ of her participants reported being blamed and $62 \%$ reported that they were discouraged from talking about their sexual assault. The discouragement came most often from their physicians or the police. In the current study, two individuals (Araceli and Dominga) were discouraged from talking about their assaults, but only one (Araceli) was discouraged by a police officer. The other was discouraged by a psychotherapist employed by the college she attended.

\subsection{Limitations of the Current Study}

Despite significant findings that contribute to the literature, a few limitations to the current study need to be stated. As a qualitative analysis, these results may point to some possible important issues for Latinas, however 
they should not be used to generalize to the broader population of Latinas in the United States without further confirmation. In addition to this basic issue, the small sample size $(n=13)$ and the recruitment process show additional limitations. The percentages included while reporting the qualitative analysis were reported on a very small set of participants and should not be viewed as quantitative findings. The study was conducted in a particular area of Michigan and, therefore, results should be applied cautiously to other places. Participants were referred from only two agencies that provided psychotherapeutic treatment programs to Latina women who selfselected. Although the group of women who participated in the current study had relatively wide diversity in terms of education, age at the time of interview, marital status, and types of assaults experienced, it is only a small representation of Latina rape survivors, which further curbs the generalizability of the findings. In other words, the women who chose to participate in this study may differ from the general population of Latina rape survivors. The youngest participants, the three 18-year-olds, gave restrained responses during their interviews. It may be beneficial to conduct more qualitative research with this population to get a fuller understanding of their experience.

Second, the sensitivity of the topic may have been a limitation to who would be willing to be respondents. Some potential participants may have chosen not to participate in this study due to their emotional state of mind and fear of retraumatization. Third, only qualitative interview data were analyzed, which may have led to meanings that were specific to this participant group or to implications about the broader population that are unfounded with interpretation of the data collected from the interviews. Other types of data might have produced different results. Thus, although participation was voluntary, the validity of the study may be limited by the bias inherent in the interview items as well as the recruitment and data collection methods used.

\subsection{Directions for Future Research}

This study has begun to fill the gap that exists in the literature on Latina victims of sexual assault. It also provides ample justification for future qualitative, quantitative or mixed studies. The topic of sexual assault and culture among female victims has relevant implications for the psychotherapy, human services, and medical fields. Violence against women should be treated as a significant social, mental, and physical problem, and sexual assaults should be viewed as a transgression against children as well as adults (Tjaden \& Thoennes, 2000). Medical personnel and psychotherapists need to be aware of all the services that are required to provide crisis and clinical services to sexually assaulted women in order to minimize further trauma and re-victimization. Culturally sensitive training in the best treatment of sexual assault victims needs to continue, and it is essential to provide women of different ethnicities with adequate services.

The results of the current study also have implications for research on other factors that may lead to sexual assault disclosure or non-disclosure or delayed disclosure for Latinas. Even though the literature on sexual assault disclosure for Latinas has been limited, what has been found is that keeping silent has been a consistent theme among Latinas who are sexually assaulted (Ramos-Lira et al., 1999). These authors also found that many Latinas blame themselves for the sexual assaults, especially if they place a high value on their virginity.

Questions recommended for future research include: What is it that needs to be in place to allow a Latina to feel safe about disclosing a sexual assault? Who needs to be available to help Latina victims? What can be said about support systems among Latina sexual assault victims? What are the differences that exist among comparison groups of sexual assault female victims? This last question may lead to a clearer understanding of the degree to which my findings are culture specific.

\section{References}

Adames, S. B., \& Campbell, R. (2005). Immigrant Latinas' Conceptualizations of Intimate Partner Violence. Violence Against Women, 11, 1341-1364. http://dx.doi.org/10.1177/1077801205280191

Ahrens, C., Isas, L., \& Viveros, M. (2011). Enhancing Latinas’ Participation in Research on Sexual Assault: Cultural Considerations in the Design and Implementation of Research in the Latino Community. Violence Against Women, 17, 177188. http://dx.doi.org/10.1177/1077801210397701

Ahrens, C., Rios-Mandel, C., Isas, L., \& del Carmen Lopez, M. (2010). Talking about Interpersonal Violence: Cultural Influences on Latinas' Identification and Disclosure of Sexual Assault and Intimate Partner Violence. Psychological Trauma: Theory, Research, Practice, and Policy, 2, 284-295. http://dx.doi.org/10.1037/a0018605

Ahrens, C. E. (2006). Being Silenced: The Impact of Negative Social Reactions on the Disclosure of Rape. American Jour- 
nal of Community Psychology, 38, 263-274. http://dx.doi.org/10.1007/s10464-006-9069-9

Ahrens, C. E., Cabral, G., \& Abeling, S. (2009). Healing or Hurtful: Sexual Assault Survivors’ Interpretations of Social Reactions from Support Providers. Psychology of Women Quarterly, 33, 81-94. http://dx.doi.org/10.1111/j.1471-6402.2008.01476.x

Ahrens, C. E., Campbell, R., Ternier-Thames, N. K., Wasco, S. M., \& Sefl, T. (2007). Deciding Whom to Tell: Expectations and Outcomes of Sexual Assault Survivors' First Disclosures. Psychology of Women Quarterly, 31, 38-49. http://dx.doi.org/10.1111/j.1471-6402.2008.01476.x

Arellano, C. M., Kuhn, J. A., \& Chávez, E. L. (1997). Psychosocial Correlates of Sexual Assault among Mexican American and White Non-Hispanic Adolescent Females. Hispanic Journal of Behavioral Sciences, 19, 446-460. http://dx.doi.org/10.1177/07399863970194004

Bachman, R. (1998). The Factors Related to rape Reporting Behavior and Arrest: New Evidence from the National Crime Victimization Survey. Criminal Justice and Behavior, 25, 8-29. http://dx.doi.org/10.1177/0093854898025001002

Campbell, R., Ahrens, C. E., Sefl, T., Wasco, S. M., \& Barnes, H. E. (2001). Social Reactions to Rape Victims: Healing and Hurtful Effects on Psychological and Physical Health Outcomes. Violence \& Victims, 16, 287-302.

Campbell, R., Wasco, S. M., Ahrens, C. E., Sefl, T., \& Barnes, H. E. (2001). Preventing the “Second Rape”: Rape Survivors' Experiences with Community Service Providers. Journal of Interpersonal Violence, 16, 1239-1259. http://dx.doi.org/10.1177/088626001016012002

Comas-Díaz, L., \& Greene, B. (1994). Women of Color: Integrating Ethnic and Gender Identities in Psychotherapy. New York: The Guilford Press.

Cuevas, C., \& Sabina, C. (2010). Final Report: Sexual Assault among Latinas (SALAS) Study.. Washington DC: U.S. Department of Justice, NCJRS Publication No. 230445. http://www.ncjrs.gov/pdffiles1/nij/grants/230445.pdf

Eadie, L. F. (2000). The Role of Self-Blame in the Treatment and Recovery of Sexual Assault Survivors: A Project upon an Independent Investigation. Unpublished Master's Thesis, Northampton, MA: Smith College School for Social Work.

Filipas, H. H., \& Ullman, S. E. (2001). Social Reactions to Sexual Assault Victims from Various Support Sources. Violence and Victims, 16, 673-692.

Fisher, B. F., Daigle, L. E., Cullen, F. T., \& Turner, M. G. (2003). Reporting Sexual Victimization to the Police and Others: Results from a National-Level Study of College Women. Criminal Justice and Behavior, 30, 6-38. http://dx.doi.org/10.1177/0093854802239161

Golding, J. M., Siegel, J. M., Sorenson, S. B., Burnam, M. A., \& Stein, J. A. (1989). Social Support Sources Following Sexual Assault. Journal of Community Psychology, 17, 92-107. http://dx.doi.org/10.1002/1520-6629(198901)17:1<92::AID-JCOP2290170110>3.0.CO;2-E

Lefley, H. P., Scott, C. S., Llabre, M., \& Hicks, D. (1993). Cultural Beliefs about Rape and Victims’ Response in Three Ethnic Groups. American Journal of Orthopsychiatry, 63, 623-632. http://dx.doi.org/10.1037/h0079477

Legislative Council, State of Michigan. The Michigan Penal Code (Excerpt), Act 328 of 1931, 750.520b, 750.520c, 750.520d, 750.520e. http://www.legislature.mi.gov

McAuslan, P. (1998). After Sexual Assault: The Relationship between Women's Disclosure, the Reactions of Others, and Health. Doctoral Dissertation, Detroit, MI: Wayne State University, Dissertation Abstracts International (UMI No. 9915701)

Morrissey, B. E. (1998). Cultural and Ethnic Variations in the Experience of Rape: Issues of Diversity in Reporting, Treatment and Coping. Unpublished Master's Thesis, Northampton, MA: Smith College School for Social Work.

Ramos-Lira, L., Koss, M. P., \& Russo, N. F. (1999). Mexican American Women’s Definitions of Rape and Sexual Abuse. Hispanic Journal of Behavioral Sciences, 21, 236-265. http://dx.doi.org/10.1177/0739986399213004

Romero, G. J., Wyatt, G. E., Loeb, T. B., Carmona, J. V., \& Solís, B. M. (1999). The Prevalence and Circumstances of Child Sexual Abuse among Latina Women. Hispanic Journal of Behavioral Sciences, 21, 351-365. http://dx.doi.org/10.1177/0739986399213009

Routbort, J. C. (1998). What Happens When You Tell: Disclosure, Attributions, and Recovery from Sexual Assault (Doctoral Dissertation, University Illinois at Chicago, 1998). Dissertation Abstracts International, 58, 5655.

Smith, D. W., Letourneau, E. J., Saunders, B. E., Kilpatrick, D. G., Resnick, H. S., \& Best, C. L. (2000). Delay in Disclosure of Childhood Rape: Results from a National Survey. Child Abuse \& Neglect, 24, 273-287. http://dx.doi.org/10.1016/S0145-2134(99)00130-1

Sorenson, S. B. (1996). Violence against Women: Examining Ethnic Differences and Commonalities. Evaluation Review, 20, 123-145. http://dx.doi.org/10.1177/0193841X9602000201

Sorenson, S. B., \& Siegel, J. M. (1992). Gender, Ethnicity, and Sexual Assault: Findings from a Los Angeles Study. Journal 
of Social Issues, 48, 93-104. http://dx.doi.org/10.1111/j.1540-4560.1992.tb01159.x

Starzynski, L. L., Ullman, S. E., Filipas, H. H., \& Townsend, S. (2005). Correlates of Women’s Sexual Assault Disclosure to Informal and Formal Support Sources. Violence and Victims, 20, 417-432. http://dx.doi.org/10.1891/0886-6708.20.4.417

Sudderth, L. (1998). "It'll Come Right Back at Me”: The Interactional Context of Discussing Rape with Others. Violence against Women, 4, 572-594. http://dx.doi.org/10.1177/1077801298004005004

Tjaden, P., \& Thoennes, N. (2000). Full Report of the Prevalence, Incidence, and Consequences of Violence against Women: Findings from the National Violence against Women Survey. Washington DC: U.S. Department of Justice, National Institute of Justice \& Centers for Disease Control and Prevention, NIJ Publication No. 183781. http://www.ncjrs.gov/pdffiles1/nij/183781.pdf

Ullman, S. E. (1996a). Correlates and Consequences of Adult Sexual Assault Disclosure. Journal of Interpersonal Violence, 11, 554-570. http://dx.doi.org/10.1177/088626096011004007

Ullman, S. E. (1996b). Do Social Reactions to Sexual Assault Victims Vary by Support Provider? Violence and Victims, 11, 143-157.

Ullman, S. E., \& Filipas, H. H. (2001). Correlates of Formal and Informal Support Seeking in Sexual Assault Victims. Journal of Interpersonal Violence, 16, 1028-1047. http://dx.doi.org/10.1177/088626001016010004

U.S. Census Bureau (2008). American Fact Finder. http://factfinder.census.gov 
Scientific Research Publishing (SCIRP) is one of the largest Open Access journal publishers. It is currently publishing more than 200 open access, online, peer-reviewed journals covering a wide range of academic disciplines. SCIRP serves the worldwide academic communities and contributes to the progress and application of science with its publication.

Other selected journals from SCIRP are listed as below. Submit your manuscript to us via either submit@scirp.org or Online Submission Portal.
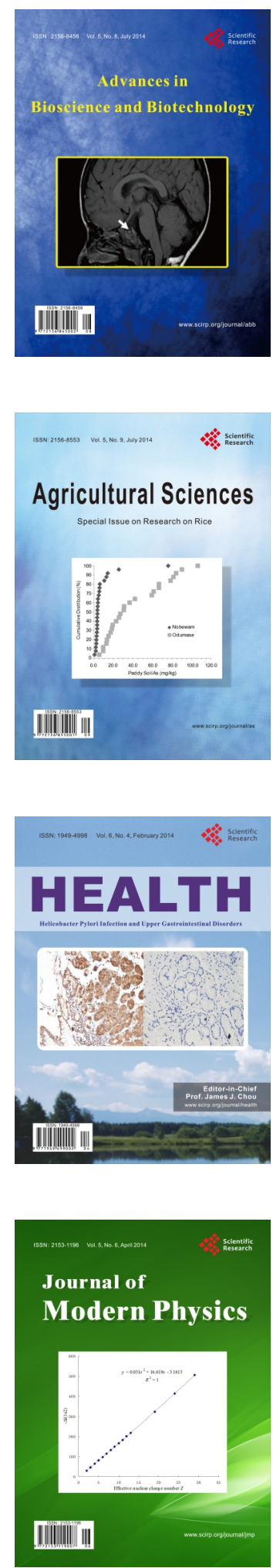
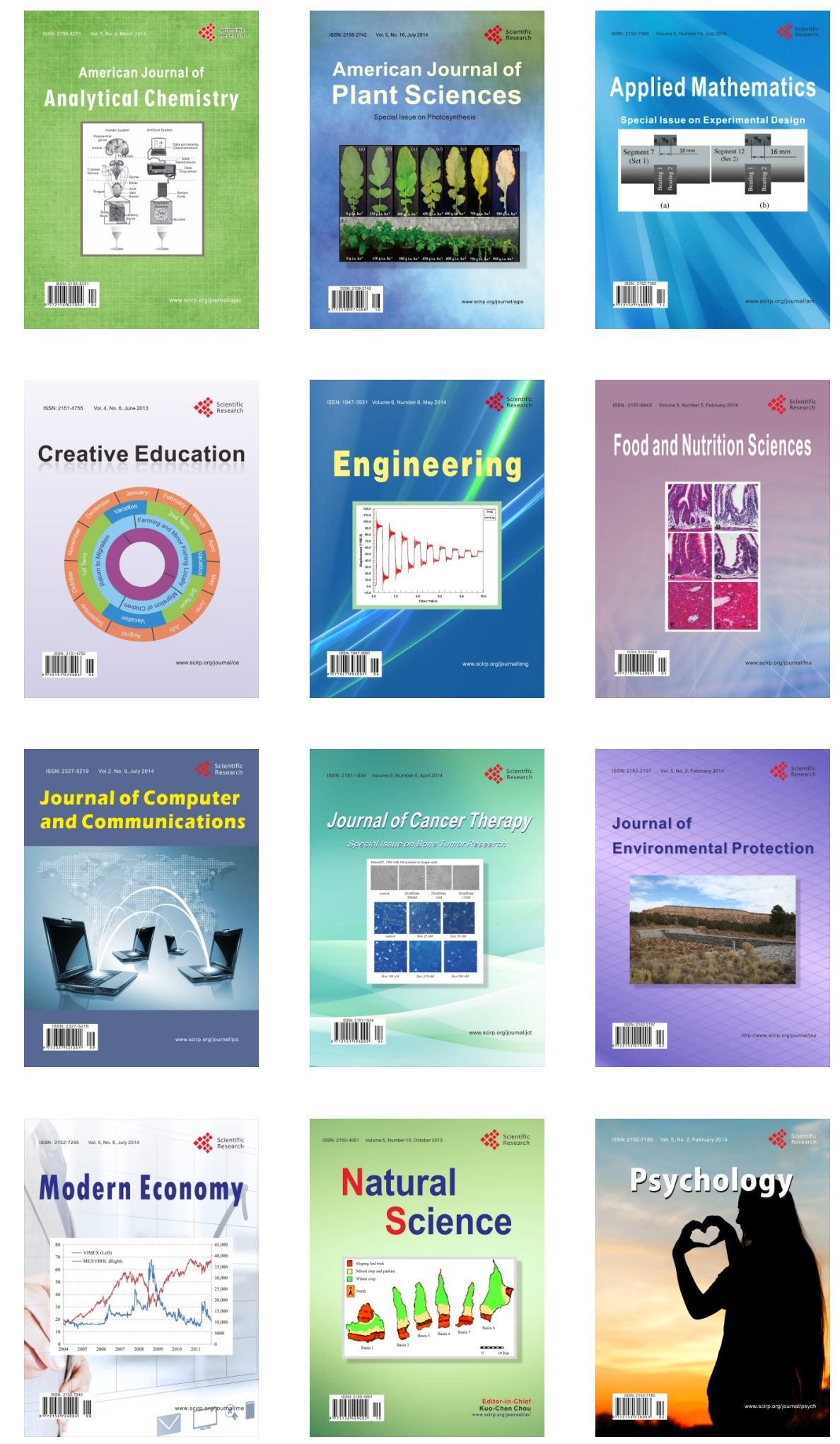